\title{
TRANSVERSE COLON DUPLICATION CYST- PRESENTING AS SUB - HEPATIC CYSTIC LESION
}

\author{
A. Narendra Kumar1, Lavanya Kannaiyan², Venkateshwar Perugu ${ }^{3}$
}

\section{HOW TO CITE THIS ARTICLE:}

A. Narendra Kumar, Lavanya Kannaiyan, Venkateshwar Perugu. "Transverse Colon Duplication CYST Presenting as Sub - Hepatic Cystic Lesion". Journal of Evolution of Medical and Dental Sciences 2015; Vol. 4, Issue 59, July 23; Page: 10383-10386, DOI: 10.14260/jemds/2015/1497

ABSTRACT: Colonic duplication cysts are rare entities. Clinical presentation depends upon the location, size and the presence of heterotropic gastric mucosa. We present a case of Transverse colon duplication cyst presenting as a subhepatic cystic lesion which was treated successfully.

KEYWORDS: Enteric duplication cyst. Abdominal cyst, colonic duplication.

INTRODUCTION: Enteric duplication cysts are rare congenital anomalies, with an estimated incidence of approximately 1 in 10,000 live births ${ }^{1}$. Colonic duplication cysts are much rarer entities. ${ }^{2}$ They vary greatly in appearance, size, location and symptoms. Presentation can occur at any age, ${ }^{3}$ but more than three quarters of those giving rise to symptoms do so in the first 2 years of life ${ }^{2}$. We present a case of colonic duplication cyst presenting as a subhepatic cystic lesion, successfully managed surgically.

CASE REPORT: A three year and half year old male child, presented to us with a history of recurrent attacks of abdominal pain for the last 3 months. Pain was colicky in nature, intermittent, lasting for half hour duration. There was a history of associated non-bilious vomiting present during attacks of pain. No history of fever, jaundice, loss of appetite or loss of weight present. Bowel habits were regular. On examination, the vital signs were stable, there was anemia or icterus. The abdomen was full, with no lump palpable, no hepatosplenomegaly. Hematological and biochemical investigations reports were within normal limits expect for a white blood cell count $\mathrm{t}(12,400 / \mathrm{cumm})$ and increased platelet count. $\mathrm{X}$-ray abdomen was normal.

Ultrasound abdomen revealed a cystic mass in the right hypochondrium below the surface of the liver, suggestive of Choledhocal cyst. Computer tomography of the abdomen reported a welldefined cystic mass lesion measuring $9 \times 4.2 \mathrm{~cm}$ (Figure 1), seen below the liver extending down to the duodenum. Contents were showing internal echoes, suggestive of Choledhocal cyst. Magnetic resonance cholangiopancreatography showed normal liver and extrahepatic biliary radiclea, a cystic nass mass in the right hypochondrium measuring $10.1 \times 4.45 \mathrm{~cm}$ with internal echoes suggestive of a teratoma or duplication cyst. With inconclusive clinical features and radiological work-up, patient was taken up for surgery.

Abdomen was explored through a right transverse supra umbilical incision. A 10x6 cm size cystic lesion was found occupying the space between liver, duodenum and transverse colon, densely adherent to all the surrounding structures (Figure 2). Upon dissection the cystic lesion was found to be sharing a common wall with the mid transverse colon (Figure 3). Complete excision of the cyst was done without colonic mucosal tear, no communication was found with the colon.

Colonic serosa was repaired. Wound closed in layers. Oral feeds was started on the $3^{\text {rd }}$ postoperative day and discharged on the $8^{\text {th }}$ post-operative day. Histopathology reported a duplication cyst with an inner lining of heterotropic gastric mucosa with a well-defined muscular outer wall. 
DISCUSSION: Enteric duplications are uncommon congenital lesions that can occur anywhere in the gastrointestinal tract from mouth to the anus and frequently they present with severe complications.

These anomalies have three defined characteristics: 1 . the presence of a well-developed smooth muscle coat, 2 . the epithelial lining represents some portion of the alimentary tract and 3. Most duplications are either cystic or tubular in shape.

Various theories have been postulated regarding the origin of duplication cyst such as:

1. Split notochord theory. 4

2. Defects of recannalisation. ${ }^{5}$

3. Remnants of intestinal diverticuli. ${ }^{6}$

Although intra-abdominal duplication cyst can give rise to symptoms at any point in life, $365 \%$ of those that present with symptoms do so within the first year of life and $87 \%$ by 2 years of age. ${ }^{2}$ This patient presented at age of $31 / 2$ years. Duplications occur more commonly in the ileum, colon being much rarer. Colonic duplications cyst usually present with features of intestinal obstruction either by direct compression, volvulous and intussusception.

In our patient since the location of the cyst was in the right hypochondrium a colonic was not suspected. USG and CT abdomen are usually aid in diagnosis of duplication cyst but in our patient they failed to do so. .,8 $^{-1}$

The cyst was found on laparotomy to be arising from the transverse colon. Histopathology confirmed the diagnosis as a duplication cyst of the colon with a inner lining by heterotropic gastric mucosa and outer serosal muscular coat ${ }^{2}$.

Although ultrasound, CT scan and MRCP contribute to the diagnosis of duplication cysts, their presentation is varied and they are often confirm upon exploration ${ }^{9}$. In conclusion a high index of suspicion is required in diagnosing subhepatic cysts as duplication cysts.

\section{REFERENCES:}

1. Ilari j, Martonell R, Morales M, Capdevila M, Mairal JA, Teixido M, Casadella A. Duplication Duedenal. Cir Pediatr 11:37-39.

2. Bond SJ, Groff DB. Gastrointestinal Duplication, in O'Neil et al (eds): Pediatric surgery, St. Louis, MO, Mosby 1998, Pg 1257-1267.

3. Hackam DJ, Zalev A, Burnstein M, et al. Enteric duplication in adult, derived from foregut, midgut and hindgut: Presentation, Patterns and literature Review. Can J Surg 40: 129-133.

4. Bentley JFR, Smith JR. Development posterior enteric remnants and spinal malformations. Arch Dis Child. 35: 76-86.

5. Breures JL. Diverticula and duplications of the intestinal tract. Arch Pathol. 38: 132-140.

6. Lewis FT, Thyng FW. Regular occurrence of intestinal diverticula in Euryliryos of pigs, rabbit and man. Am J Anal. 7: 505-519.

7. Barr LL, Hayden CK, Stasberry SD et al. Enteric duplication cysts in children: Are their abdominal wall charcteretistics diagnostics? Pediatr Radiol. 20: 326-328.

8. Lamont AC, Starinsky R, Cremin BJ. Ultrasonic diagnosis of duplication cysts in children. Br J Radiol. 57: 463-467. 


\section{CASE REPORT}

9. Ildstad ST, Tollerud DJ, Weiss RG, Ryan DP, McGowan MA, Martin LW. Duplications of the alimentary tract, clinical characteristics, preferred treatment and associated malformations. Ann Surg. 208: 184-189.

Figure 1: CT abdomen showing a cystic mass below the liver extending upto the duodenum.

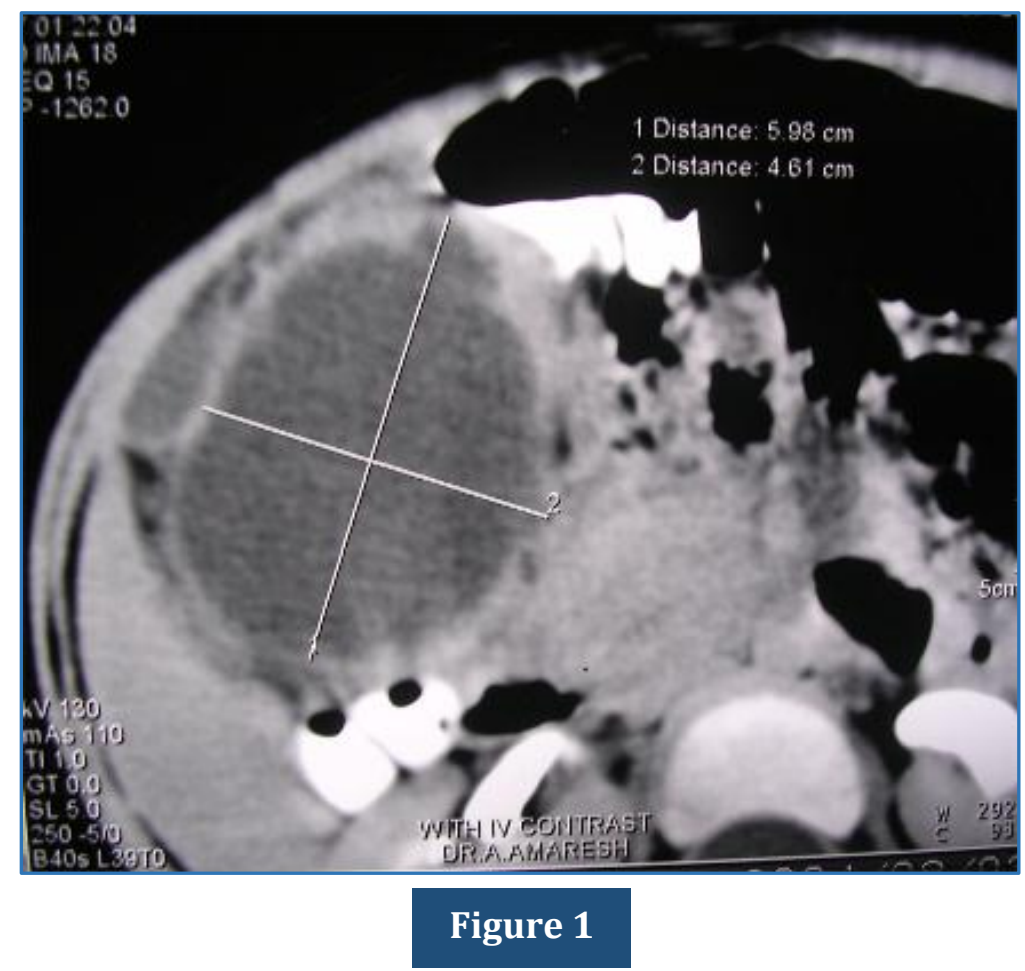

Figure 2: Clinical photograph showing the intra-abdominal cystic lesion.

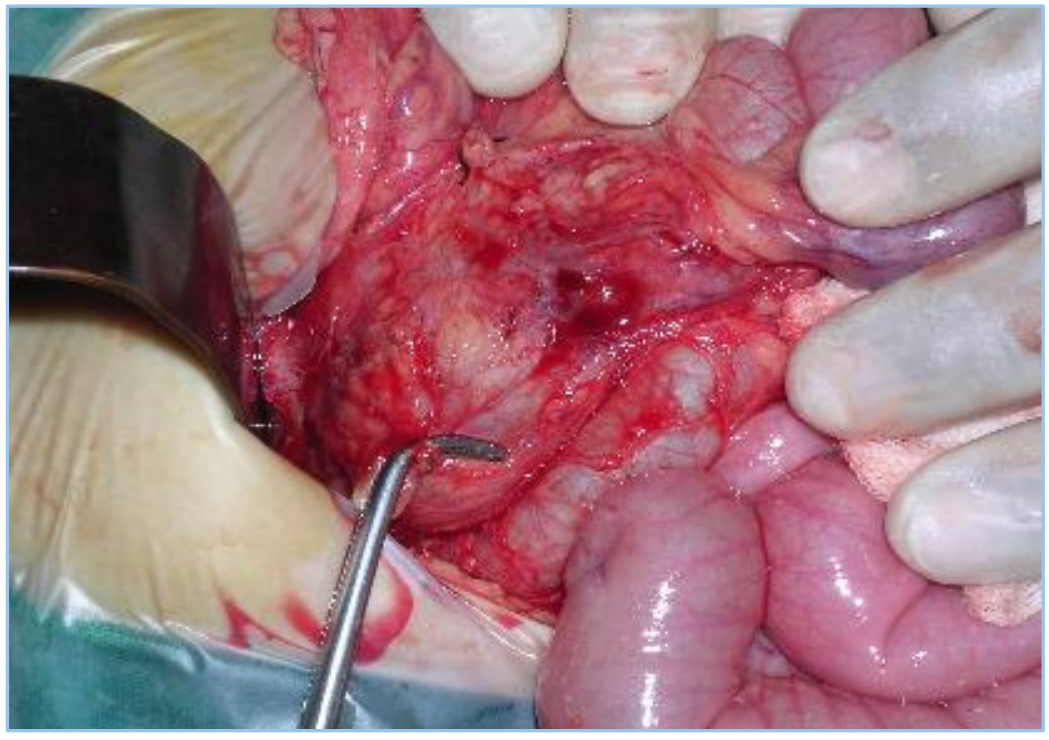

Figure 2 


\section{CASE REPORT}

Figure 3: Clinical photograph showing the cystic mass sharing a common wall with the colon.

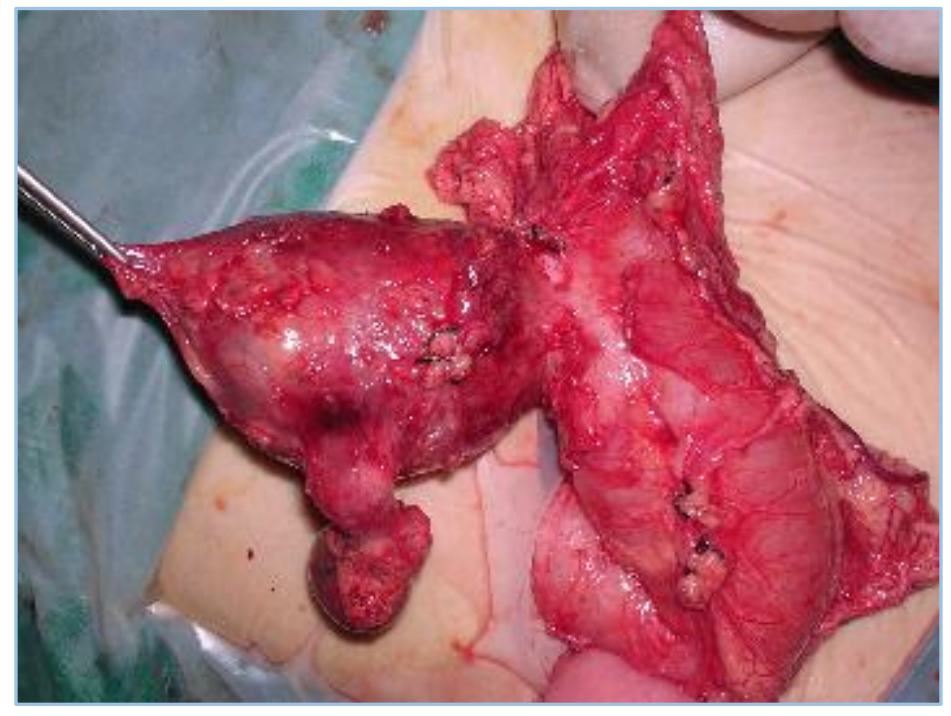

\section{Figure 3}

\section{AUTHORS:}

1. A. Narendra Kumar

2. Lavanya Kannaiyan

3. Venkateshwar Perugu

\section{PARTICULARS OF CONTRIBUTORS:}

4. Chief Pediatric Surgeon, Department of Paediatric Surgery, Lotus Children's Hospital, Hyderabad, Telangana, India.

5. Pediatric Surgeon, Department of Paediatric Surgery, Lotus Children's Hospital, Hyderabad, Telangana, India.

\section{FINANCIAL OR OTHER} COMPETING INTERESTS: None
3. Pediatric Surgeon Department of Paediatric Surgery, Lotus Children's Hospital, Hyderabad, Telangana, India.

\section{NAME ADDRESS EMAIL ID OF THE CORRESPONDING AUTHOR:}

Dr. A. Narendra Kumar, 304, Lake Villa Apartments, 6-3-1186/87, Green Lands, Begumpet, Hyderabad-500016, Telangana, India.

E-mail: naren.are.1961@gmail.com

Date of Submission: 24/06/2015. Date of Peer Review: 25/06/2015. Date of Acceptance: 16/07/2015. Date of Publishing: 23/07/2015. 